\title{
Forest carbon accounting methods and the consequences of forest bioenergy for national greenhouse gas emissions inventories
}

Jon McKechnie ${ }^{1,}{ }^{*}$, Steve Colombo ${ }^{2}$, Heather L. MacLean ${ }^{3}$

1. Division of Energy \& Sustainability, University of Nottingham, Nottingham UK, NG7 2RD

2. Ontario Forest Research Institute, Ontario Ministry of Natural Resources, Sault Ste. Marie, Canada, P6A 2E5

3. Department of Civil Engineering and Department of Chemical Engineering and Applied Chemistry, University of Toronto, Toronto Canada, M5S 1A4

* Corresponding author jon.mckechnie@nottingham.ac.uk (+44) (0) 1157484435

\begin{abstract}
While bioenergy plays a key role in strategies for increasing renewable energy deployment, studies assessing greenhouse gas (GHG) emissions from forest bioenergy systems have identified a potential trade-off of the system with forest carbon stocks. Of particular importance to national GHG inventories is how trade-offs between forest carbon stocks and bioenergy production are accounted for within the Agriculture, Forestry and Other Land Use (AFOLU) sector under current and future international climate change mitigation agreements. Through a case study of electricity produced using wood pellets from harvested forest stands in Ontario, Canada, this study assesses the implications of forest carbon accounting approaches on net emissions attributable to pellets produced for domestic use or export. Particular emphasis is placed on the Forest Management Reference Level (FMRL) method, as it will be employed by most Annex I nations in the next Kyoto Protocol Commitment Period. While bioenergy production is found to reduce forest carbon sequestration, under the FMRL approach this trade-off may not be accounted for and thus not incur an accountable AFOLU-related emission, provided that total forest harvest remains at or below that defined under the FMRL baseline. In contrast, accounting for forest carbon trade-offs associated with harvest for bioenergy results in an increase in net GHG emissions (AFOLU and life cycle emissions) lasting 37 or 90 years (if displacing coal or natural gas combined cycle generation, respectively). AFOLU emissions calculated using the Gross-Net approach are dominated by legacy effects of past management and natural disturbance, indicating near-term net forest carbon increase but longer-term reduction in forest carbon stocks. Export of wood pellets to EU markets does not greatly affect the total life cycle GHG emissions of wood pellets. However, pellet exporting countries risk creating a considerable GHG emissions burden, as they are responsible for AFOLU and bioenergy production emissions but do not receive credit for pellets displacing fossil fuel-related
\end{abstract}


GHG emissions. Countries producing bioenergy from forest biomass, whether for domestic use or for export, should carefully consider potential implications of alternate forest carbon accounting methods to ensure that potential bioenergy pathways can contribute to GHG emissions reduction targets.

\section{Introduction}

Electricity generation from forest biomass offers the potential to reduce greenhouse gas (GHG) emissions relative to fossil fuel generation, while also addressing sustainability concerns such as nonrenewable resource use, air pollutant emissions, and energy security. The flexibility of bioenergy as a potential alternative energy source for heat, transport, and electricity applications has led to its inclusion in national strategies for reducing GHG emissions and increasing renewable energy penetration (e.g., UK DECC, 2012). Risks associated with forest bioenergy production, in particular the impact on forest carbon sequestration and potential GHG emissions consequences, have been identified in several studies (e.g., Searchinger et al., 2009; McKechnie et al., 2011; Vanhala et al., 2013). Of particular importance to national GHG inventories is how trade-offs between forest carbon stocks and bioenergy production are accounted for within current and future international climate change mitigation agreements.

Under the United Nations Framework Convention on Climate Change, bioenergy systems straddle the Energy sector and the Agriculture, Forestry and Other Land Use (AFOLU) sector, with the latter accounting for terrestrial carbon stocks. To avoid double-counting, $\mathrm{CO}_{2}$ emissions from biomass combustion are excluded from GHG accounting within the energy sector. Implications of these emissions on atmospheric GHGs are assessed indirectly through terrestrial carbon stock accounting under the AFOLU sector. Conventional life cycle assessment methods similarly do not account for biomass-based $\mathrm{CO}_{2}$ emissions in the assessment of bioenergy systems. Life cycle studies commonly assume that these emissions are balanced by post-harvest biomass regrowth and thus do not contribute to atmospheric GHGs (e.g., Zhang et al., 2010). Research has highlighted the possible shortcomings of this accounting approach, as it risks omitting potentially significant carbon stock changes resulting from bioenergy production (e.g., Searchinger et al., 2008). Recent studies of bioenergy have developed integrated life cycle and forest carbon analysis methods to include forest carbon impacts within life cycle studies (e.g., McKechnie et al., 2011; Helin et al., 2013). Net GHG emissions, inclusive of life cycle activities and forest carbon impacts, are time dependent: forest carbon removals at harvest are compensated by forest regrowth, which occurs over a comparatively long timescale. Trade-offs between forest biomass-based bioenergy production and forest carbon 
stocks have been found to result in increased GHG emissions relative to fossil fuels lasting decades to more than 100 years (e.g., Kayo et al., 2011; McKechnie et al., 2011; Ter-Mikaelian et al., 2011). Lacking in prior applications of integrated life cycle/forest carbon analysis methods is a consideration of how trade-offs between bioenergy and forest carbon would be accounted for under climate change mitigation agreements and national emissions inventories. Accounting for forest carbon stocks within GHG emissions inventories is complex, due in part to the long-term consequences of previous management decisions and natural disturbances (Bottcher et al., 2008). Accounting rules have been proposed and prior studies have evaluated the implications of these rules on the assessed GHG emissions/sinks for managed forests (e.g., Bottcher et al., 2008; Ellison et al., 2011). Under the $2^{\text {nd }}$ Commitment Period of the Kyoto Protocol, most reporting nations have chosen to measure forest carbon stock changes by first identifying a Forest Management Reference Level (FMRL) to define a dynamic, forward looking baseline to which future forest carbon stocks are compared (UNFCCC 2013). While alternate accounting methods can greatly impact assessed AFOLU emissions (Bottcher et al., 2008), implications of accounting methods on the emissions attributable to forest bioenergy have yet to be investigated.

The North American wood pellet industry has grown rapidly in response to demand in domestic and export markets (FBN, 2013), fuelled in part by initiatives in EU countries to implement biomass cofiring and repowering of coal generating stations to meet renewable energy and GHG emissions reduction targets. Alongside potential pellet sources in the US Southeast (e.g., Dwivedi et al., 2014), wood pellet export from Ontario, Canada, to international markets is developing as a supply chain (Rentech, 2014). It is thus important to understand the potential implications of wood pellet production and trade for producer country's national emissions inventories. The objective of this study is to investigate how forest carbon accounting approaches employed within the AFOLU sector might impact emissions attributable to forest bioenergy within national emissions inventories. We expand on existing life cycle and forest carbon analysis models to quantify AFOLU emissions resulting from forest bioenergy production under three alternative forest carbon accounting methods. This novel assessment approach is applied to a case study of wood pellet production from harvested forest stands in the Great Lakes-St. Lawrence Forest Region of Ontario, Canada. Life cycle GHG emissions are quantified for both domestic pellet consumption and export of pellets to a hypothetical EU consumer to compare implications for Canada's emissions inventory.

\section{Forest Carbon Accounting Approaches}


Forest carbon accounting approaches are designed to quantify the impact of management (e.g., deforestation/afforestation; harvest/renewal) on atmospheric GHGs. Applied nationally, these approaches determine the net GHG emissions sink (or source) related to forests, a component of the AFOLU sector, for inclusion in national inventories. While forest carbon accounting approaches are not designed to assess the impact of a particular forest product, we adapt these methods, as described below, to better understand the implications of increased forest resource utilisation for bioenergy production. Forest carbon accounting approaches have been described in detail elsewhere (e.g., Bottcher et al., 2008). A simple and general representation of changes in forest carbon stocks that would be accountable within national inventories, as either an emissions source or sink, can be presented by:

$$
\Delta C_{\text {acc }}=\Delta C_{\text {obs }}-\Delta C_{\text {base }}
$$

where $\Delta C_{a c c}$ is the accountable change in forest carbon stocks over a set period of time, $\Delta C_{\text {obs }}$ is the observed change in forest carbon taking into account actual forest management practices, and $\Delta C_{\text {base }}$ is the projected change in forest carbon stocks under a defined baseline, or business-as-usual management scenario.

Forest carbon accounting approaches differ primarily by how they define the baseline forest condition and this aspect can have a significant impact on the quantification of AFOLU emissions (Bottcher et al., 2008). A similar issue has been identified in assessing emissions reductions from avoiding deforestation and forest degradation (REDD): calculated emissions credits are highly dependent on the selected baseline to which future forest carbon stocks are compared (Huettner et al., 2009; Griscom et al., 2009; Sloan and Pelletier, 2012).

In this study, we consider three alternative forest carbon accounting baselines:

1. Forest management reference level, a forward-looking and dynamic baseline that predicts future forest carbon stocks under 'business-as-usual' forest management assuming future and historical harvest rates to be equal;

2. Gross-net, a static baseline that assumes no change in forest carbon stocks from the level at the start of a commitment period; and

3. Incremental carbon impact, a second forward-looking and dynamic baseline that predicts future forest carbon stocks resulting from ongoing production of 'conventional' wood products (lumber, pulp, paper, etc.) but specifically excludes changes in forest carbon due to future harvest for bioenergy production, which is considered additional to the baseline. 


\subsection{Forest Management Reference Level Baseline}

The forest management reference level (FMRL) baseline is a forward-looking dynamic baseline, defined by projected forest carbon stocks under 'business-as-usual' management practices. Accountable changes in forest carbon stocks are then calculated as the difference between observed forest carbon stocks and projected stocks under the FMRL baseline (Eq'n 1). Most reporting countries have employed a FMRL baseline in assessing forest carbon-related emissions and sinks under the $2^{\text {nd }}$ Commitment Period of the Kyoto Protocol (UNFCCC 2013). Assessing forest carbon stock changes relative to a FMRL baseline has the advantage of factoring out the effects of forest age structure (a result of past management activities and disturbances), thereby isolating the effects of contemporary forest management practices on forest carbon stocks.

The definition of the FMRL baseline is constrained under the Kyoto Protocol to exclude the effects of domestic policies initiated after 2009 and requiring countries to justify how their proposed FMRL baseline represents business-as-usual practices. However, countries have an incentive to project high forest harvest levels within the FMRL baseline, thereby maximising forest carbon sequestration credits (when projected harvest levels are not met) or avoiding accountable forest-carbon related emissions if harvest does increase to such levels in the future (Greenglass et al., 2010; Freiden et al., 2012). To avoid potential manipulation, Greenglass et al. (2010) propose that the FMRL baselines be quantified based on average historical harvest rates. A number of countries, including Canada, have employed historical harvest data to establish FMRLS (UNFCCC, 2011).

\subsection{Gross-Net Baseline}

The Gross-Net baseline was used to account for forest carbon stock changes in the 1st Commitment Period of the Kyoto Protocol. This approach accounts for all changes in forest carbon stocks over a commitment period. The Gross-Net baseline is static, defined simply as the forest carbon stock at the beginning of the commitment period or at a specified reference year. Thus, as the reference baseline does not include any change in forest carbon stocks (from Equation 1, $\Delta C_{\text {base }}=0$ ), accountable GHG emissions/sinks are quantified as the change in observed forest carbon stocks.

By accounting for all changes in forest carbon over a commitment period, the Gross-Net approach provides a direct measure of the change in existing forest carbon stocks over time. However, changes in forest carbon stocks quantified in this manner are inclusive of legacy effects originating from management activities and natural processes occurring prior to the commitment period (for 
example see Ter-Mikaelian et al., 2013). The impacts of contemporary forest management can therefore not be isolated with the Gross-Net approach.

\subsection{Incremental Carbon Impact Baseline}

Numerous assessments of the trade-offs between forest carbon stocks and emerging bioenergy products (e.g., wood pellets, ethanol) have considered harvesting for bioenergy production to be 'additional' to business-as-usual forest management (McKechnie et al., 2011; Zanchi et al., 2012; Walker et al., 2013). We term this baseline definition the 'Incremental Carbon Impact' baseline. Similar to the FMRL baseline, the Incremental Carbon Impact baseline defines a dynamic reference baseline based on business-as-usual practices. However, the reference baseline is defined as excluding activities related to increased use of forest biomass for bioenergy applications. Any additional harvest for bioenergy production is thus assumed to exceed the business-as-usual baseline, which prior studies have found to result in a reduction in forest carbon stocks. As such, the Incremental Carbon Impact approach accounts for foregone forest carbon sequestration that would have occurred in the absence of wood pellet production. The Incremental Carbon Impact approach is not considered by UNFCCC as an AFOLU accounting option, but is included here to enable comparison with prior studies.

\section{Case study of Wood Pellet Production}

We undertake a case study of wood pellet production in the Great Lakes-St. Lawrence Forest Region of Ontario, Canada for both domestic and export markets to demonstrate possible implications for Canada's GHG emissions inventory. The case study quantifies two means by which wood pellet production and use can impact national GHG emissions inventories: 1) avoiding fossil fuel use and associated emissions; and 2) changing the amount of carbon stored in forest biomass and soils (dependent on forest carbon accounting approach).

The scenarios considered are:

1. Wood pellet, domestic use: wood pellet production and combustion in a retrofit coal generating station in Ontario, Canada, displacing:

i. Reference coal: combustion of coal in an existing coal generating station in Ontario

ii. Reference natural gas: combustion of natural gas in a new build combined cycle facility in Ontario 
2. Wood pellet, export: wood pellet production in Ontario and delivery to point of export at Quebec City

For both the domestic and export cases, GHG emissions associated with activities related to forest management (harvest, regeneration), wood pellet manufacture, and domestic logistics would be accountable under Canada's emissions inventory (Figure 1). The domestic use of wood pellets to avoid fossil fuel consumption would reduce GHG emissions reported in Canada's energy sector. When pellets are produced for export, only forest management, wood pellet manufacture, and domestic transport and handling activities are relevant to Canada's emissions inventory (Figure 1b). International transport of pellets, as with all international shipping activities, falls outside of national emissions inventories (Heitmann and Khalilian, 2011). GHG emissions associated with pellet transport and use within the consuming country, including emissions reductions associated with the displacement of fossil fuels, would be accounted for within the importing country's inventory.

\subsection{Biomass sources}

Biomass is assumed to be sourced from harvested forest stands in the Great Lakes-St. Lawrence region. Competition between alternative uses for forest resources (e.g., conventional forestry products; carbon sequestration credits) is not considered in developing the hypothetical biomass availability scenario considered here. Biomass availability for pellet production is constrained so that the total harvest volume for conventional products (lumber, pulp and paper) and wood pellets does not exceed the average historical harvest rate between 1998 and 2007. Biomass availability for pellets is thus quantified as the difference between the longer perspective historical average harvest rate (1998 to 2007) and the lower recent harvest rate (2008-2010), providing an average annual biomass availability of $470,000 \mathrm{odt} / \mathrm{yr}$. Recent harvesting is assumed to be undertaken for conventional wood products only; this demand is assumed to remain constant throughout the 100year study period. Increased demands for some conventional products (e.g., lumber) are possible; however, there is greater doubt surrounding the recovery of other forest product sectors (e.g., pulp and paper). Projections of future timber harvesting in the Great Lakes-St. Lawrence region for conventional forestry products manufacture are not available and are beyond the scope of the present study.

Projected harvesting for conventional products and wood pellet manufacture are simulated using the Strategic Forest Management Model (SFMM) timber supply model as described by McKechnie et al. (2011). These projections are then employed to estimate biomass availability for pellets as 
described above. Biomass availability, presented on an oven-dry tonne (odt) basis, accounts speciesspecific parameters (moisture content, density) and a "biomass expansion factor" to account for tree components that are suitable for pellet production but would not be included in measurements of merchantable volume harvested (McKechnie et al., 2011). The species composition of timber destined for wood pellet production varies for some management units over the 100-year period, resulting in some variation in biomass availability on an odt basis (See Supporting Information, Table S1).

\subsection{AFOLU emissions: Application of forest carbon baselines}

Forest carbon baselines are developed for each accounting approach detailed in Section 2 to assess the impact of wood pellet production on AFOLU-related emissions under potential future accounting approaches. Baselines are defined at the beginning of the 100-year study period based upon historical harvest data and projected future forest carbon stocks. The 100-year study period is divided into 10-year sub-periods to provide a simple representation of future 'commitment periods' under the Kyoto Protocol or a successor agreement. Baselines are updated the beginning of each new decadal 'commitment period' (e.g., baselines are recalculated in year 2020, 2030). As future GHG emissions agreements have not been settled, the definitions of accounting methods and associated forest carbon reference baselines are by nature hypothetical but are developed to illustrate emissions that may be accountable to wood pellet production within the AFOLU sector under a set of possible future accounting rules.

The FMRL baseline is defined as the projected forest carbon stocks assuming the ongoing constant timber volume harvest at the average historical harvest rate observed between 1998 and 2007 in the Great Lakes St. Lawrence Forest. As the historical harvest rate is assumed to be maintained throughout the model period, recalculation of the historical average harvest rate at the beginning of each future decade returns the same reference harvest rate. The chosen baseline is similar to the FMRL in Canada's 2011 UNFCCC submission, which defines the baseline as the average national harvest rate from 1990 to 2009 (UNFCCC, 2013a). The shorter reference period employed here corresponds to the scenario investigated previously in McKechnie et al. (2011) and thus enables easier comparison with prior results. Implications of formulating the FMRL baseline using different historic harvest data are discussed in Section 5.

Using the same volume harvest rates and resulting forest carbon stocks as in the FMRL approach, we applied the Gross-Net approach to compare observed forest carbon stocks with a static reference, 
defined in the present study as the total forest carbon stock at the beginning of each decade. The Gross-Net reference baseline is updated for each 10-year sub-period of the study, based on projected forest carbon stocks at the start of each decade.

The Incremental Carbon Impact baseline is defined based on continued forest management activities in the absence of any harvesting for wood pellet production, as in McKechnie et al. (2011). Harvest for wood pellet production is considered additional to the baseline. Any associated reductions in forest carbon stocks are attributed to wood pellets as an emissions source.

\subsection{Forest carbon analysis}

Forest carbon dynamics related to timber harvesting for wood pellet production are assessed using the FORCARB-ON model (Chen et al., 2010). FORCARB-ON is a forest carbon model developed to assess carbon stocks under different management scenarios and has been used previously in assessing forest carbon impacts of bioenergy systems (McKechnie et al., 2011; Ter-Mikaelian et al., 2012; Colombo et al., 2012). FORCARB-ON is employed to quantify future forest carbon stocks associated with wood pellet and conventional forest product production and the reference baseline forest carbon stocks used in the alternative accounting approaches. AFOLU-related emissions are assessed for each accounting approach as described in Sections 2 and 3.2.

Application of the forest carbon accounting approaches returns AFOLU emissions of forest management as a whole. We allocate a portion of these emissions to wood pellet manufacture to assess the specific implications of this emerging forest product. Due to the strict definition of biomass supply, no accountable change in forest carbon is generated when employing the FMRL method, thus allocation is a moot point. In the Gross-Net method, AFOLU emissions must be allocated between conventional products and wood pellets. We employ mass-based allocation, whereby AFOLU emissions are allocated to wood pellets based on the relative mass of total harvest that is input to wood pellet production. A mass basis is selected as a conservative approach to estimating AFOLU-related emissions; a financial basis, for example, would attribute a smaller fraction of forest carbon related emissions to bioenergy due to the lower market value of biomass relative to saw logs. Allocation is not required for the Incremental Carbon Impact method as this approach isolates the forest carbon implications of bioenergy production.

\subsection{Life cycle assessment of Wood Pellet and Reference Fossil Fuel Pathways}


Life cycle inventory models are developed to quantify GHG emissions associated with the wood pellet production and use pathways: wood pellet manufacture, transport, electricity generation, and avoided emissions associated with using pellets in place of fossil fuels. Activities for all pathways include resource extraction, fuel processing, combustion, and all transport stages. The functional unit of the life cycle component of this study is one kWh of electricity produced. Emissions of selected $\mathrm{GHG}$ emissions $\left(\mathrm{CO}_{2}, \mathrm{CH}_{4}, \mathrm{~N}_{2} \mathrm{O}\right)$ are evaluated as $\mathrm{CO}_{2}$ eq. on the basis of 100 -year global warming potentials (IPCC, 2006). Biomass-based $\mathrm{CO}_{2}$ emissions are not accounted for in the life cycle component, but instead in the forest carbon analysis, following the integrated life cycle assessment/forest carbon analysis approach defined in McKechnie et al (2011).

Life cycle models are developed from existing models and databases (e.g., Zhang et al., 2010; NRCan, 2013). Energy use and GHG emissions related to forest operations (harvesting, renewal), wood pellet manufacture, transport to domestic point of use, and combustion for electricity generation were evaluated in Zhang et al. (2010). The present study updates the model to reflect more recent data on the Ontario electricity grid mix (IESO, 2013) and emissions factors for the production and use of fossil fuels (NRCan, 2012). Inputs and GHG emissions data associated with wood pellet manufacture and transport are presented in the Supporting Information (Table S2).

Electricity generation efficiency using coal (35\%) is assumed to decrease to $33 \%$ when using $100 \%$ wood pellets. Non- $\mathrm{CO}_{2} \mathrm{GHG}$ emissions from biomass combustion are assessed based on database values (NRCan, 2013). Life cycle GHG emissions associated with the coal-fired generation reference pathway were evaluated previously (Zhang et al. 2010). Electricity generation via natural gas combined cycle is modelled using existing databases (NRCan, 2012), assuming a generation efficiency of $47 \%$.

When wood pellets are produced for export, only domestic activities are relevant to Canada's national inventory (Section 3 and Figure 1). For the export case a truncated LCA is undertaken, limited to activities from forest to port (Figure 1b). Pellets destined for export are assumed to be shipped by rail (average distance 1,030 km from hypothetical Ontario mills) to the Port of TroisRivieres, Quebec, which is already active in pellet export (Trebio, 2014), where they would be subsequently loaded for international shipment. The remainder of the activities (e.g., international shipping, pellet combustion - Figure 1b) are not accountable within Canada's national inventory: international shipping is not accounted for under UNFCCC guidelines (Heitmann and Khalilian, 2011); pellet combustion and fossil fuel displacement is accounted for by the consuming country. 


\section{Results}

\subsection{AFOLU emissions}

Forest carbon stocks are presented in Figure 2 for the three forest carbon accounting approaches. Observed forest carbon (solid grey line) indicates the expected forest carbon stock when both conventional forest products and wood pellets are produced over the 100-year period as described in Section 3. Observed forest carbon stocks increase between 2010 and 2030, decline to 2070, and then increase again up to 2110 . These general trends represent the long-term implications of past forest management and natural processes on forest carbon dynamics; increasingly over time, the effects of future harvest also impact forest carbon modelled in the current study.

The FMRL baseline (Figure 2a) is co-incident with the observed forest carbon stock over time. This results from the strict definition of biomass availability in this study, which maintains total harvest (conventional products + bioenergy) at the historic harvest rate defined between 1998 and 2007, corresponding to the FMRL baseline. As such, there is no difference between observed and FMRL baseline carbon stocks at any point over the 100-year model period. In contrast, the Gross-Net baseline (Figure $2 \mathrm{~b}$ ) is defined as the starting forest carbon stock at the beginning of each decadal 'commitment period'. Observed forest carbon stocks are expected to match or exceed the Gross-Net baseline between 2010 and 2030, indicating a net forest carbon sink. In subsequent decades up to 2070 , observed carbon stocks are in deficit to the baseline, which indicates a forest carbon-related emissions source. From 2070 to the end of the model period, a net carbon sink is again achieved. Under the Incremental Carbon Impact method (Figure 2c), all harvesting for wood pellet production is 'additional' to the reference baseline. As a result, observed forest carbon stocks are in deficit to the reference baseline throughout the 100 -year study period, indicating a AFOLU-related emissions source.

\subsection{Life cycle and total greenhouse gas emissions}

Life cycle GHG emissions from electricity generation using wood pellets and reference fossil fuels (coal, natural gas) domestically, exclusive of forest carbon impacts, are presented in Figure 3 . These results are similar to prior studies (Zhang et al., 2010; McKechnie et al., 2011), with a small improvement in GHG emissions reductions due to lower upstream emissions from wood pellet manufacture in the present study. Relative to the coal reference pathway, domestic use of wood pellets reduces GHG emissions by $92 \%$. Displacing electricity generated by the natural gas combined- 
cycle pathway results in a smaller GHG emissions reduction (84\%) for the domestic wood pellet pathway.

Life cycle results are converted to a basis of $\mathrm{tCO}_{2}$ eq./odt $t_{\text {biomass }}$ to assess the effectiveness of biomass use in reducing GHG emissions by these pathways and to enable results to be integrated with those from forest carbon analysis. Domestic use of wood pellets displacing coal avoids 1.49 $\mathrm{tCO}_{2}$ eq./odt $t_{\text {biomass }}$ while displacing natural gas avoids $0.64 \mathrm{tCO}_{2}$ eq./odt $\mathrm{t}_{\text {biomass. }}$

Net GHG emissions accountable within Canada's GHG inventory for wood pellet production and domestic use in electricity generation are shown in Figure 4a,b. Results are shown as cumulative net emissions, taking into account life cycle emissions and accountable AFOLU emissions. Under the FMRL method, forest stand harvest for wood pellet production does not result in a AFOLU emissions source attributable to wood pellets at any point during the 100 year study period. As such, only life cycle emissions associated with wood pellet production and use in place of fossil fuels impact net emissions. Forest carbon results for the FMRL method do not indicate an absence of forest carbon reductions from producing wood pellets. Rather, the reduction in forest carbon caused by harvest for pellets is simply not counted as an emission under the FMRL method due to the total harvest not exceeding of the baseline. Wood pellet production and domestic use results in net emissions reductions of 0.6 to $0.8 \mathrm{Mt} \mathrm{CO}$ eq./yr (Figure $5 \mathrm{a}$, displacing coal) and $0.3 \mathrm{MtCO}_{2} \mathrm{eq} . / \mathrm{yr}$ (Figure $5 \mathrm{~b}$, displacing natural gas). Over 100 years of production, wood pellets cumulatively avoid approximately $70 \mathrm{MtCO}_{2}$ eq. and $30 \mathrm{MtCO}_{2}$ eq. when displacing coal and natural gas, respectively. To put these values in perspective, Canada's national emissions for 2011 totalled $702 \mathrm{Mt} \mathrm{CO}_{2} \mathrm{eq}$ (UNFCCC, 2013).

Employing the Gross-Net method results in the attribution of forest carbon-related sinks and emissions to wood pellet production at different points over the 100 -year study period. These AFOLU emissions are driven predominately by long-term implications of past forest management practices and natural processes on forest carbon dynamics that are largely independent of the decision to produce wood pellets. AFOLU emissions attributed under the Gross-Net method counteract emissions reductions from pellet use displacing fossil fuels on the medium-term (2040 to 2080), but at no point is a net GHG emissions increase observed. Cumulative avoided emissions by the end of the 100-year study period total $62 \mathrm{MtCO}_{2} \mathrm{eq}$. (displacing coal) and $23 \mathrm{MtCO}_{2} \mathrm{eq}$. (displacing natural gas). 
In contrast to the FMRL approach, by definition the Incremental Carbon Impact approach fully accounts for the trade-off between forest carbon stocks and additional harvest for wood pellet production. Forest carbon-related emissions quantified by the Incremental Carbon Impact method initially exceed avoided emissions from displacing fossil fuel use, resulting in an initial net increase of emissions lasting approximately 37 years (displacing coal) and 90 years (displacing natural gas). Over the 100-year study period, cumulative avoided emissions of $41 \mathrm{MtCO}_{2}$ eq. and $2 \mathrm{MtCO}_{2}$ eq. are achieved when displacing coal and natural gas, respectively.

The net GHG emissions accountable within Canada's GHG inventory for wood pellet export are shown in Figure 4c. Net GHG emissions results generally indicate a net emissions source (positive value) throughout the 100 -year model timeframe for all three methods, due primarily to emissions savings from pellets displacing fossil fuels not being accountable within Canada's GHG inventory. AFOLU-related emissions are dependent on the selected forest carbon accounting approach and follow results shown in Figure 2. Employing the FMRL method results in no AFOLU-related emissions being attributed to wood pellet production and thus domestic emissions are limited to life cycle GHGs from forest management, wood pellet manufacture, and domestic logistics. As with the domestic case, AFOLU emissions calculated using the Gross-Net approach are dominated by the long-term implications of past management and natural processes. The general trend of increasing forest carbon stocks to 2040 results in a net emission reduction over this period, after which net emissions increases are attributed to wood pellets. In contrast to the FMRL approach, the Incremental Carbon Impact approach accounts for foregone forest carbon sequestration that would have occurred in the absence of wood pellet production. This approach reveals substantial AFOLUrelated emissions resulting in a large net GHG emissions source of up to $33 \mathrm{Mt} \mathrm{CO}_{2}$ eq. over the 100year study period. In context, Canada's reported AFOLU emissions related to forestry indicated a net emissions source from forests totalling $287 \mathrm{Mt} \mathrm{CO}$ eq over the 22 years between 1990 and 2011 (UNFCCC, 2013).

\section{Discussion}

Although trade-offs between forest carbon stocks and bioenergy production have been assessed previously, such studies have not considered the potential implications of different forest carbon accounting approaches on emissions attributable to bioenergy within the AFOLU sector. This study indicates that the selection of forest carbon accounting method can greatly impact emissions attributed to bioenergy production and Canada's emissions inventory, ranging from immediate and significant avoided emissions cumulating to a 100 -year GHG reduction of $70 \mathrm{Mt} \mathrm{CO}_{2}$ eq (FMRL 
approach) to an initial GHG increase lasting 37 years and significantly smaller 100-year GHG reduction of $41 \mathrm{MtCO}_{2}$ eq. when displacing coal in domestic use. Application of the FMRL method, the approach adopted by most Annex I countries for the $2^{\text {nd }}$ Commitment Period of the Kyoto Protocol, indicates that wood pellets can be produced with nil AFOLU-related emissions (despite changes in forest carbon due to harvesting) so long as total harvest for conventional and bioenergy products is constrained at or below the FMRL baseline. In such a scenario, trade-offs between forest carbon and bioenergy are not accountable as an emissions source and wood pellets result in immediate emissions reductions when displacing fossil fuels. We emphasize that this result does not mean that bioenergy production from harvested forest stands could be undertaken without consequence to forest carbon stocks, but instead that this trade-off may not be counted as an emission due to the choice of forest carbon accounting method.

Forest carbon trade-offs should not be ignored, even if they do not result in an accountable AFOLU emission. Non-accountable forest carbon consequences can be considered as an 'opportunity cost' to evaluate mutually-exclusive alternatives of forest stand harvest for bioenergy or foregoing this harvest. In the present study, greater GHG mitigation can initially be achieved through increasing forest carbon stocks; however, beyond 37 years (pellets displacing coal) and 90 years (pellets displacing natural gas), using wood pellets to avoid fossil fuel use provides greater emissions reductions. Whether the longer-term net GHG emissions reductions of forest bioenergy outweigh the foregone opportunity to sequester more forest carbon is a question of debate that should be considered alongside other factors influencing forest management decisions and associated policies (e.g., forest sector employment and ecological sustainability). Ideally, forest resource utilisation decisions and related policies should be informed by comprehensive cost-benefit analysis. However, reliance of key parameters on national and international regulations, and the possibility such policies can quickly change, introduces additional uncertainty to completing a robust cost-benefit analysis. In the current study we identify accounting method selection as a primary factor in quantifying GHG implications of bioenergy harvest. Other highly relevant parameters depend heavily on policies: for example, the value of carbon offsets via forest carbon sequestration (dependent on the design of emissions trading schemes); and the market value of bioenergy products (influenced by domestic and international policies incentivising and/or mandating increased penetration of renewable energy).

Alongside GHG emissions, tools to assess the climate impacts of forest harvest should be developed to incorporate climate-relevant biophysical impacts of forest management (e.g., e.g. Betts, 2000; 
Jackson et al., 2008; Bright et al., 2011; Anderson-Teixeira et al., 2012; Rogers et al., 2013). In particular, biophysical impacts may serve to counteract forest carbon trade-offs associated with forest harvesting in northern latitudes. Adapting existing assessment approaches to represent forest management and translating stand-level results to regional and global perspectives in a format suitable for integration with existing emissions accounting frameworks would provide more complete understanding of the climate impacts of forest management and, by extension, forest bioenergy systems.

Results for all AFOLU forest carbon accounting approaches are dependent on the definition of the reference baseline. In particular, the definition of 'business-as-usual' management could significantly impact the reference harvest level projected within the FMRL baseline. In the present study, the reference baseline is defined based on historical harvest between 1998 and 2007. During this time, annual harvest varied significantly, from 2.6 million $\mathrm{m}^{3} / \mathrm{yr}$ (2007) to 3.6 million $\mathrm{m}^{3} / \mathrm{yr}$ (2005). Defining the baseline over a different time period could affect reference annual harvest rates. Activities included within the reference baseline may also vary. At present, baseline definition is rather liberal, with countries required only to justify how their proposed baseline represented business-as-usual practices and exclude the effects of domestic policies initiated after 2009. This has resulted in some countries projecting increased harvest levels within their FMRL baselines, a practice which is controversial (e.g., Greenglass, 2010). Whereas some countries are experiencing increased demand for forest resources that may continue, inclusion of such activities runs contrary to emissions accounting undertaken outside of the AFOLU sector (e.g., electricity sector cannot alter a 'reference emissions level' because of increasing demand for electricity).

As illustrated in this case study, the emissions burden placed on countries producing wood pellets is quite small when considering only energy and material inputs to domestic activities within the full life cycle. However, harvesting forest stands reduces stored carbon and can forego forest carbon sequestration; accounting for this implication in assessing wood pellet production from harvesting forest stands reveals significant emissions burdens. Depending on the accounting method employed for forest carbon this result highlights a potential risk to wood pellet producing countries in meeting emissions reduction targets when pellets are sourced by harvesting forest stands. In addition, the ability to eventually achieve carbon parity when wood pellets are sourced from standing trees depends on regenerating forests that will be productive for decades after harvesting; potential negative impacts of climate change on forests (Allen et al. 2010; Peng et al. 2011) means that such an assumption is not certain. In this event, the assumed benefits of bioenergy from harvested forest 
stands displacing fossil fuels would probably not be realized. For these reasons, policy makers aiming to develop domestic and export pellet markets should encourage this be done in ways minimizing reductions in forest carbon stocks, while ensuring associated economic benefits can compensate for forgoing additional carbon sequestration in forests.

\section{Acknowledgements}

We thank the Ontario Ministry of Natural Resources and the Natural Sciences and Engineering Research Council for financial support and Michael Ter-Mikaelian for his valuable insights on an earlier draft of this paper.

\section{References}

Allen CD, Macalady AK, Chenchouni H, Bachelet D, McDowell N, Vennetier M, Kitzberger T, Rigling A, Breshears DD, Hogg EH, Gonzalez P, Fensham R, Zhang Z, Castro J, Demidova N, Lim J-W, Allard G, Running SW, Semerci A, Cobb N (2010) A global overview of drought and heat-induced tree mortality reveals emerging climate change risks for forests. Forest Ecology and Management, 259, 660-684.

Anderson-Teixeira KJ, Snyder PK, Twine TE, Cuadra SV, Costa MH, DeLucia EH (2012) Climateregulation services of natural and agricultural ecoregions of the Americas. Nature Climate Change, 2, 177-181.

Betts RA (2000) Offset of the potential carbon sink from boreal forestation by decreases in surface albedo. Science, 408, 187-191.

Bottcher H, Kurz, WA, Freibauer, A (2008) Accounting of forest carbon sinks and sources under a future climate protocol - factoring out past disturbance and management effects on age-class structure. Environmental Science \& Policy, 11, 669-686.

Bright RM, Stromman, AH, Peters, GP (2011) Radiative forcing impacts of boreal forest biofuels: A scenario study for Norway in light of albedo. Environmental Science \& Technology, 45, 7570-7580.

Chen J, Colombo SJ, Ter-Mikaelian MT, Heath LS (2010). Carbon budget of Ontaro's managed forests and harvested wood products, 2001-2100. Forest Ecology and Management, 259, 1385-1398.

Colombo SJ, Chen J, Ter-Mikaelian M, McKechnie J, Elkie PC, MacLean HL, Heath LS (2012) Forest protection and forest harvest as strategies for ecological sustainability and climate change mitigation. Forest Ecology and Management, 281, 140-151.

Dwivedi P, Khanna M, Bailis R, Ghilardi A (2014) Potential greenhouse gas benefits of transatlantic wood pellet trade. Environmental Research Letters, 9, 11pp.

Ellison D, Lundblad, M, Petersson, $\mathrm{H}$ (2011) Carbon accounting and the climate politics of forestry. Environmental Science \& Policy, 14, 1062-1078.

Forest Business Network (2013) Exportation of wood pellets from North America to Europe reached a new record of 3.2 million tons in 2012. April 28. Accessed 15/05/2014. Available at: 
http://www.forestbusinessnetwork.com/27490/exportation-of-wood-pellets-from-north-americato-europe-reached-a-new-record-of-3-2-million-tons-in-2012/

Freiden D, Pena N, Bird DN (2012) Incentives for the use of forest biomass: a comparative analysis of Kyoto Protocol accounting pre- and post-2012. Greenhouse Gas Measurement and Management, 2, 84-92.

Greenglass N, Funk J, Caum M, Houghton RA (2010) Fixing a flawed approach to forest accounting in the next round of the Kyoto Protocol. Carbon Management, 1, 179-182.

Griscom B, Shoch D, Stanley B, Cortez R, Virgilio N (2009) Sensitivity of amounts and distribution of tropical forest carbon credits depending on baseline rules. Environmental Science \& Policy, 12, 897911.

Heitmann N, Khalilian S (2011) Accounting for carbon dioxide emissions from international shipping: Burden sharing under different UNFCCC allocation options and regime scenarios. Marine Policy,

Helin T, Sokka L, Soimakallio S, Pingoud K, Pajula T. (2012). Approaches for inclusion of forest carbon cycle in life cycle assessment-a review. Global Change Biology Bioenergy, 5, 475-486.

Huettner M, Leemans R, Kok K, Ebeling J (2009) A comparison of baseline methodologies for 'Reducing Emissions from Deforestation and Degradation'. Carbon Balance and Management, 4, $12 p$.

Independent Electricity System Operator (IESO) (2013) Ontario's Independent Electricity System Operator releases 2012 electricity production, consumption, and price data. $11^{\text {th }}$ January, 2013. http://www.ieso.ca/imoweb/news/newsltem.asp?newsltemID=6323

Intergovernmental Panel on Climate Change (IPCC) (2006). Guidelines for National Greenhouse Gas Inventories; Eggleston, S., Eds.; Institute for Global Environmental Strategies: Hayama, Japan.

Jackson RB, Randerson JT, Canadell JG, Anderson RG, Avissar R, Baldocchi DD, Bonan GB, Caldeira K, Diffenbaugh NS, Field CB, Hungate BA, Jobbagy EG, Kueppers LM, Nosetto MD, Pataki DE (2008) Protecting climate with forests. Environmental Research Letters, 3, 6p.

Manomet Center for Conservation Sciences (2010) Biomass sustainability and carbon policy study.

McKechnie J, Colombo S, Chen J, Mabee W, MacLean HL (2011) Forest bioenergy or forest carbon? Assessing trade-offs in greenhouse gas mitigation with wood-based fuels. Environmental Science \& Technology, 45, 789-795.

Natural Resources Canada (NRCan) (2012) GHGenius - a model for life cycle assessment of transportation fuels, Version 4.02.

Peng C, Ma Z, Lei X, Zhu Q, Chen H, Wang W, Liu S, Li W, Fang X, Zhou X (2011) A drought-induced pervasive increase in tree mortality across Canada's boreal forests. Nature Climate Change, 1, 467471.

Rentech (2014) Wood pellets (International Sales). Accessed 15/05/2014. Available at: http://www.rentechinc.com/wood-pellets-international.php 
Rogers BM, Randerson JT, Bonan GB (2013) High-latitude cooling associated with landscape changes from North American boreal forest fires. Biogeosciences, 10, 699-718.

Searchinger TD, Hamburg SP, Melillo J, Chameides W, Havlik P, Kammen, DM, Likens, GE, Lubowski RN, Obersteiner M, Oppenheimer M, Robertson GP, Schlesinger WH, Tilman, G.D (2009) Fixing a critical climate accounting error. Science, 326, 527.

Searchinger T, Heimlich R, Houghton RA, et al. (2008) Use of US croplands for biofuels increases greenhouse gases through emissions from land-use change Science, 319, 1238-1240.

Sloan S, Pelletier J (2012) How accurately may we project tropical forest-cover change? A validation of a forward-looking baseline for REDD. Global Environmental Change, 22, 440-453.

Ter-Mikaelian, MT, Colombo SJ, Chen J. (2013) Effects of harvesting on spatial and temporal diversity of carbon stocks in a boreal forest landscape. Ecology and Evolution. doi: 10.1002/ece3.751.

Ter-Mikaelian M, McKechnie J, Colombo SJ, Chen J, MacLean HL (2011) The carbon neutrality assumption for forest bioenergy: A case study for Northwestern Ontario. Forestry Chronicle, 87, 644652.

Trebio (2014). Trebio Renewable Biomass. Accessed 15/05/2014. Available at: http://www.trebio.ca/about-trebio-woodpellets/

UK Department of Energy \& Climate Change (2012) UK Bioenergy Strategy. Accessed 18/13/2014. Available at: https://www.gov.uk/government/uploads/system/uploads/attachment data /file/48337/5142-bioenergy-strategy-.pdf

United Nations Framework Convention on Climate Change (2013) Forest Management Reference Levels. Ad Hoc Working Group on Further Commitments for Annex I Parties under the Kyoto Protocol (AWG-KP). Accessed 27/03/2013. Available at: http://unfccc.int/bodies/awg-kp/items/5896.php

United Nations Framework Convention on Climate Change (2011) Canada. Report of the technical assessment of the forest management reference level submission of Canada submitted in 2011. Accessed 27/03/2013. Available at: http://unfccc.int/resource/docs/2011/tar/can01.pdf

United Nations Framework Convention on Climate Change (2013) National Inventory Submissions 2013. Accessed 21/03/2014. Available at:

http://unfccc.int/national_reports/annex_i_ghg_inventories/national_inventories_submissions/item s/7383.php

Vanhala P, Repo A, Liski J (2013) Forest bioenergy at the cost of carbon sequestration? Current Opinion in Environmental Sustainability, 5, 41-46.

Wiser R, Barbose, G. (2008) Renewables Portfolio Standards in the United States. Lawrence Berkeley National Laboaratory, LBNL-154E.

Zanchi G, Pena N, Bird N (2012) Is woody bioenergy carbon neutral? A comparative assessment of emissions from consumption of woody bioenergy and fossil fuel. Global Change Biology Bioenergy,

4, 761-772 
Zhang Y, McKechnie J, Cormier D, Lyng R, Mabee W, Ogino A, MacLean HL (2010) Life cycle emissions and cost of producing electricity from coal, natural gas, and wood pellets in Ontario, Canada.

Environmental Science and Technology,44, 538-544. 
A

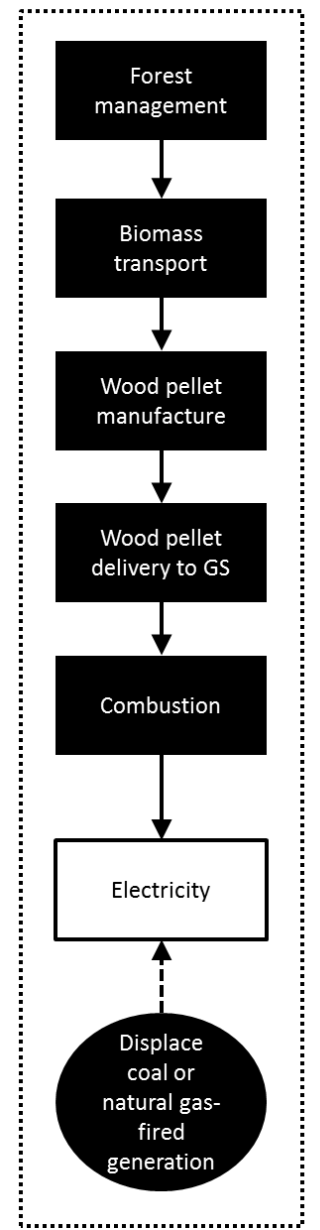

B

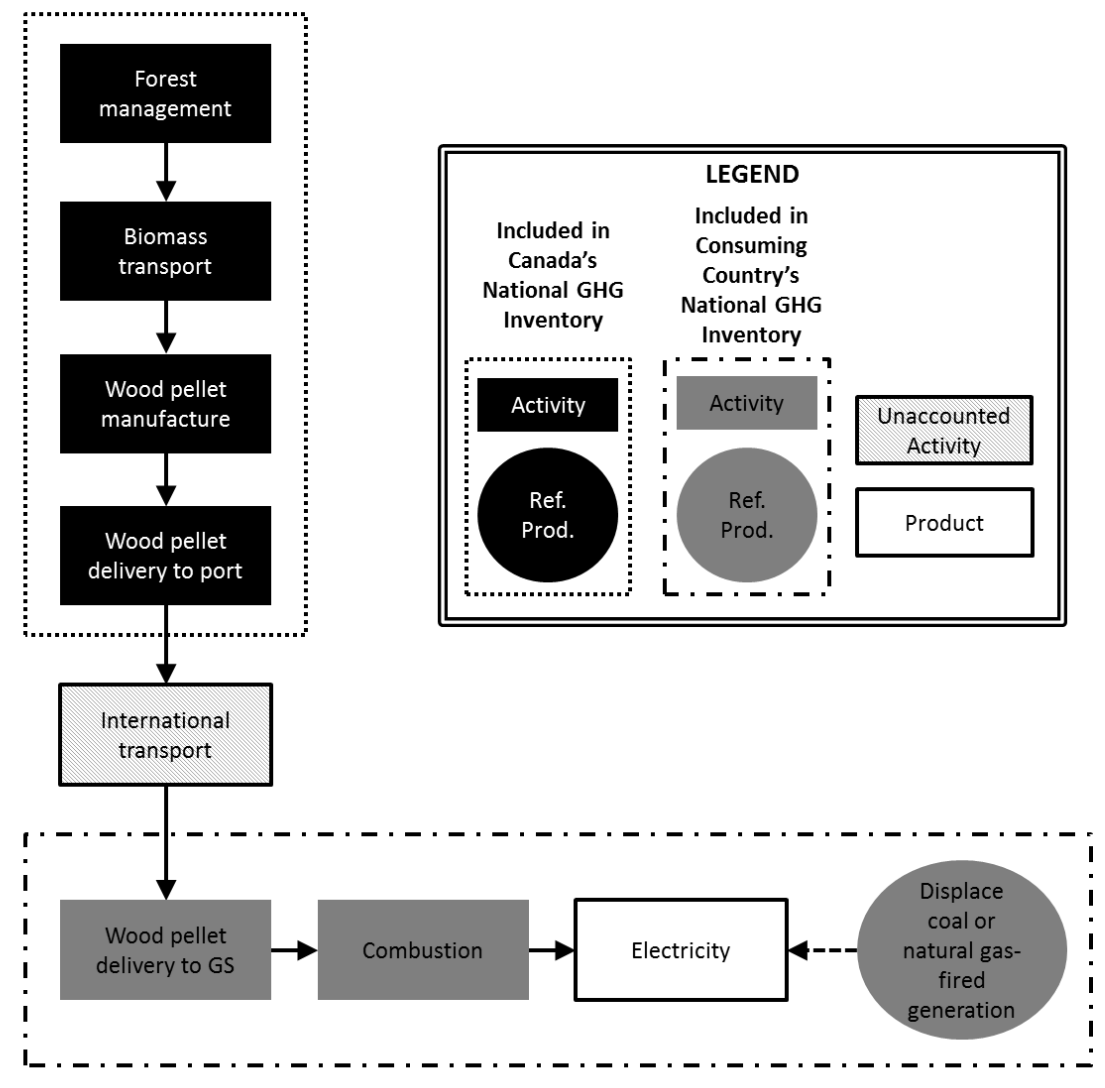

Figure 1. Comparison of life cycle activities included in national GHG emissions inventories of the Domestic Market and Export Market. A: manufacture of wood pellets for domestic use in electricity generation; B: manufacture of wood pellets for export markets and use in electricity generation. Ref. Prod.: Reference product 
A

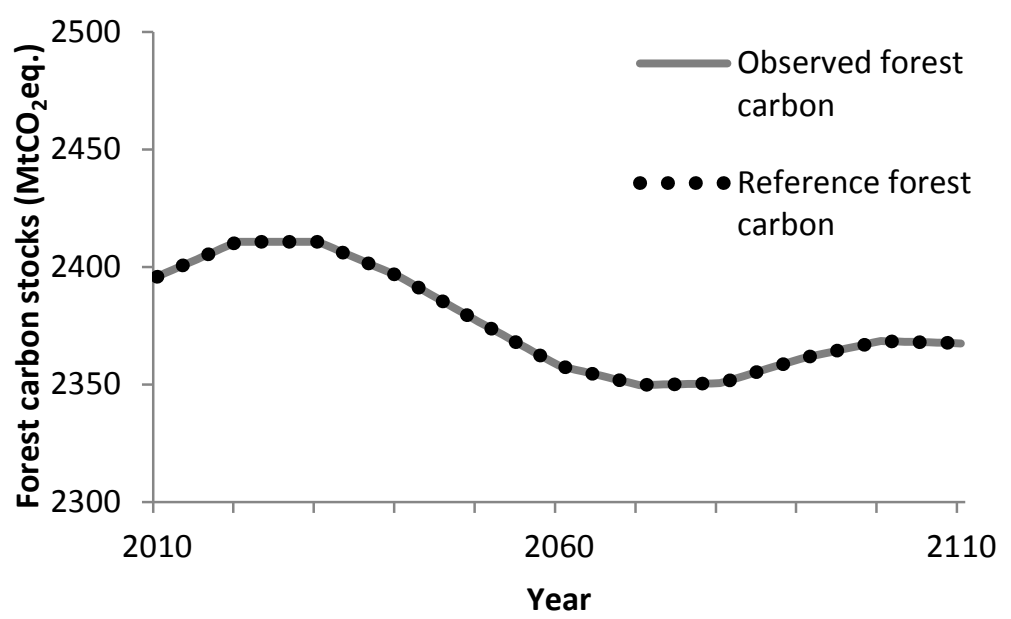

B

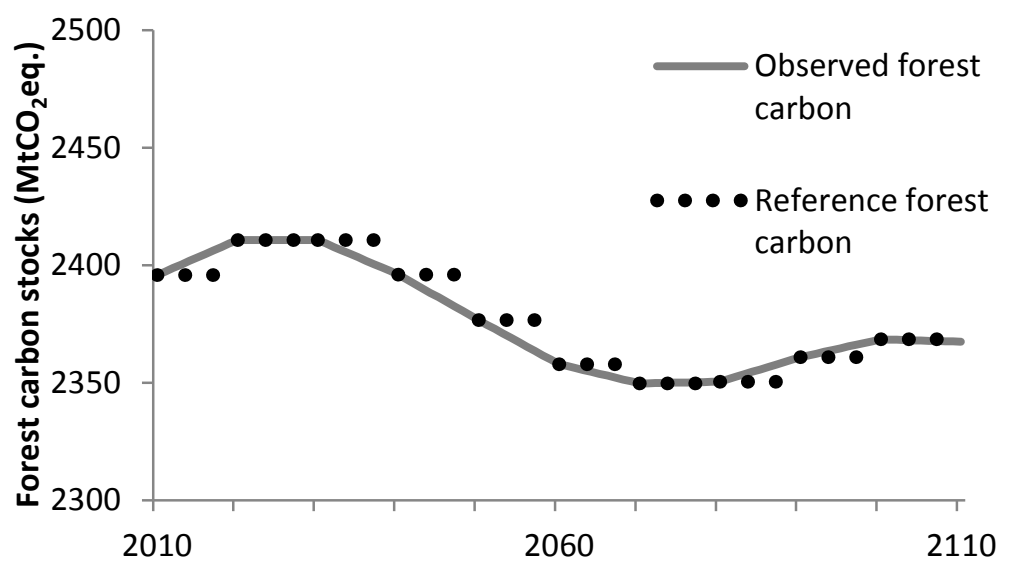

C

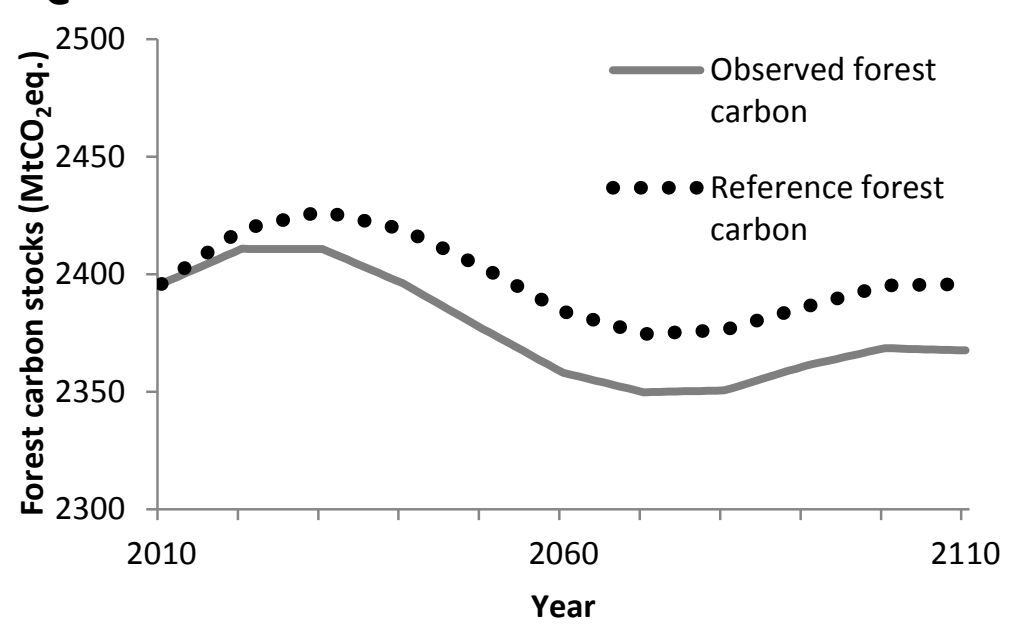

Figure 2. Projected forest carbon stocks and reference baselines under alternate forest carbon accounting approaches. A: Forest Management Reference Level (FMRL), B:GrossNet, C: Incremental Carbon Impact. 


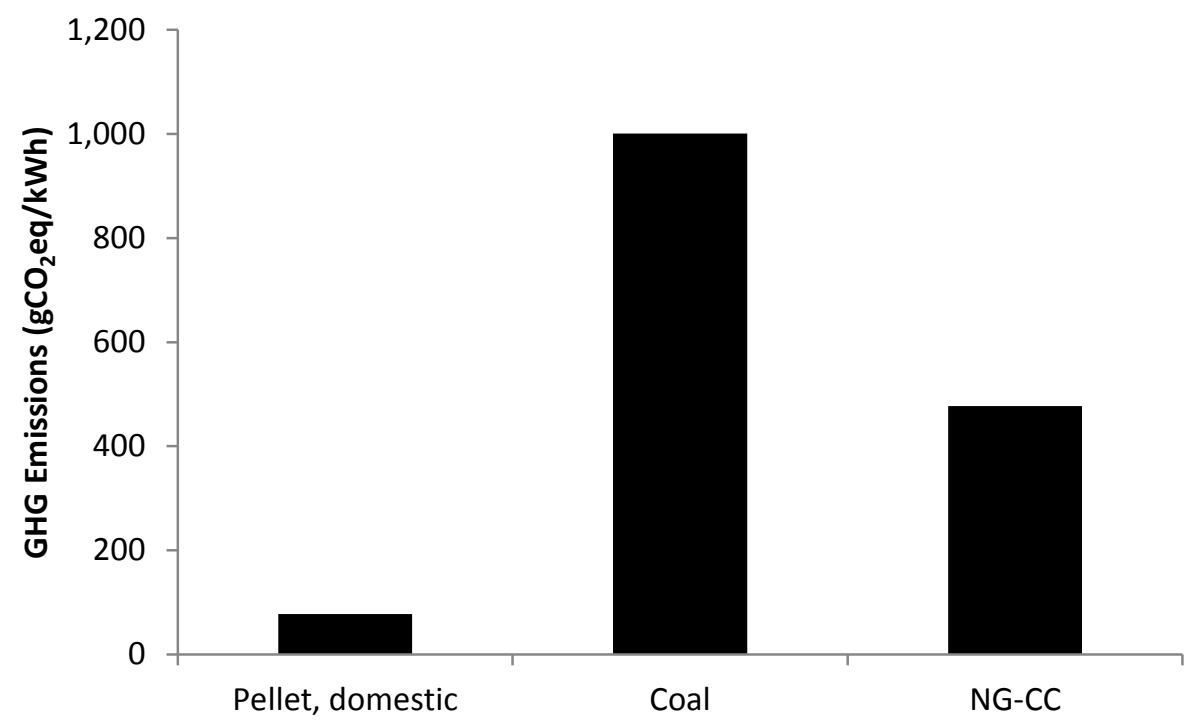

Figure 3. Life cycle GHG emissions of domestic wood pellet use for electricity generation and comparison with reference fossil fuel generation pathways. Exclusive of AFOLU forest carbon-related emissions. 


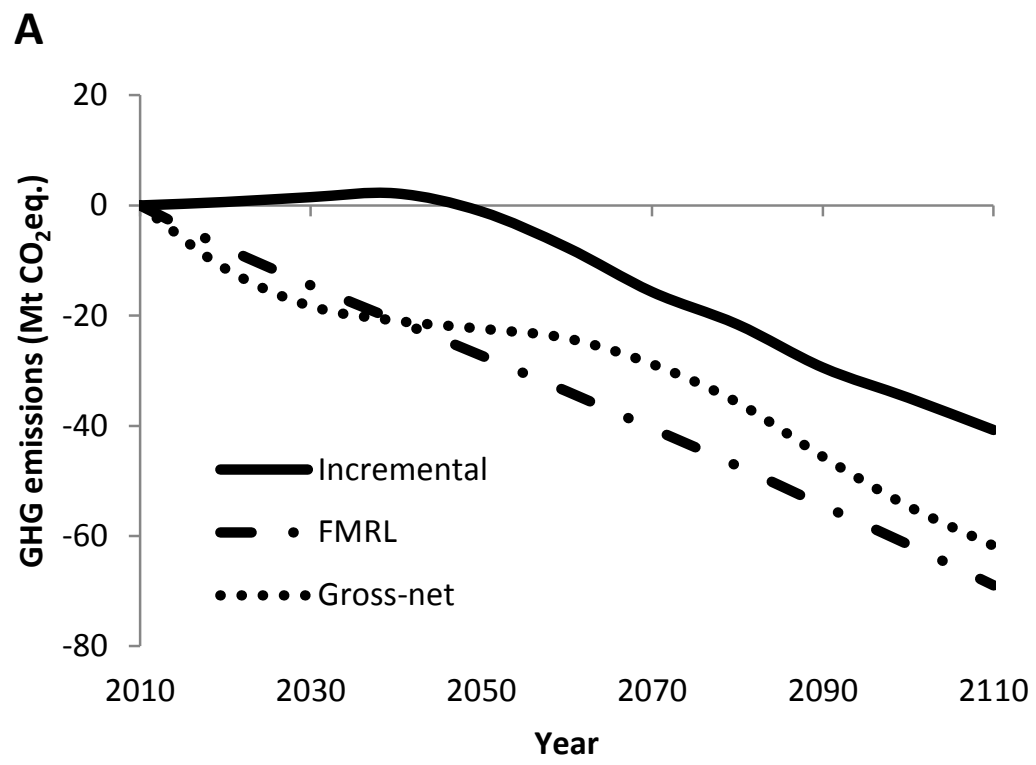

B
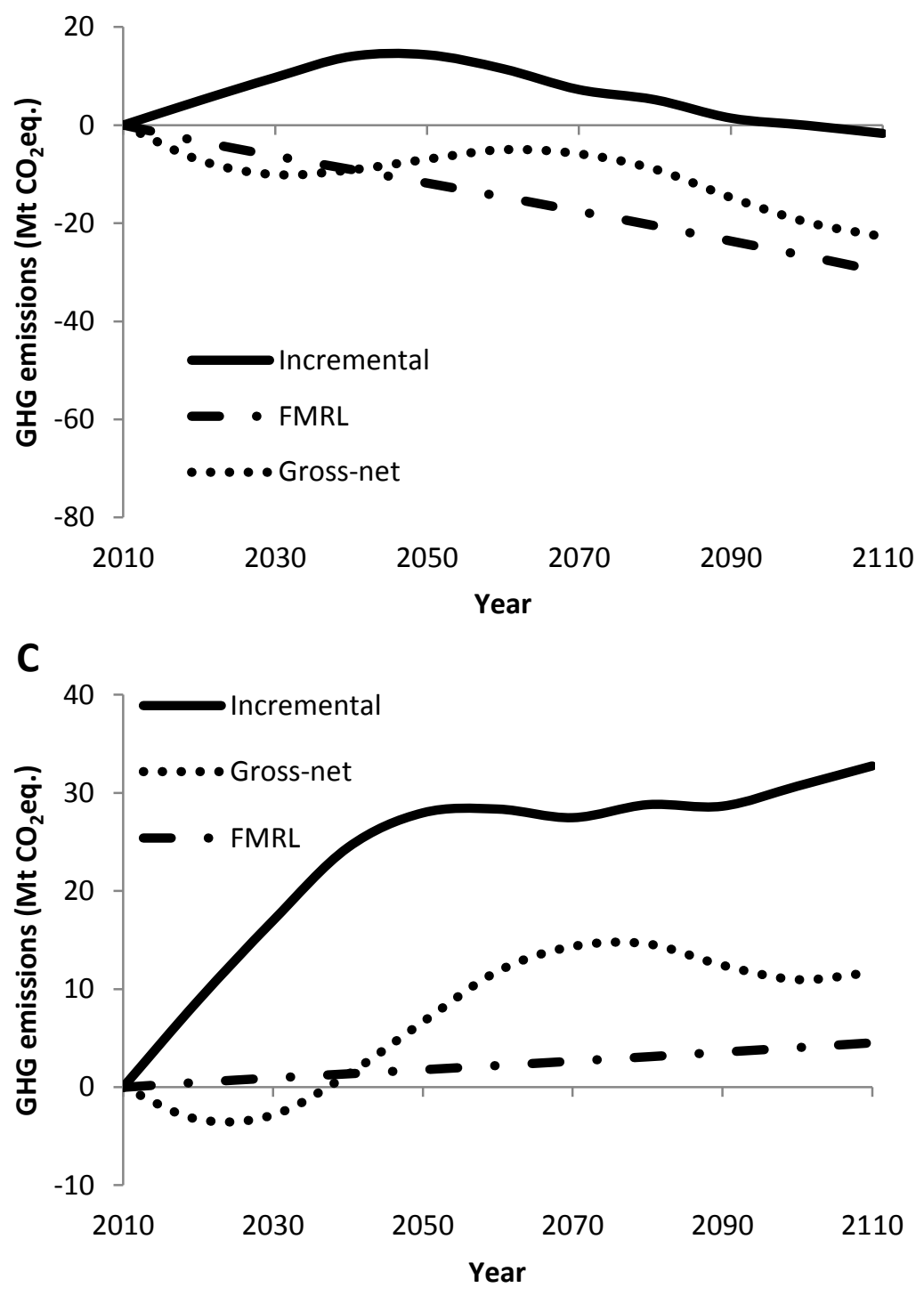

Figure 4. Net accountable GHG emissions within Canada's GHG inventory, inclusive of domestic life cycle GHG emissions and AFOLU forest carbon-related GHG emissions. A: domestic use, wood pellets 
displacing coal. B: domestic use, wood pellets displacing natural gas combined cycle. C: domestic production and export. 